\title{
The Economic Burden of Illness in Pediatric Acute Lymphoblastic Leukemia (ALL) Patients from a Commercial and Medicaid Insurance Perspective
}

\author{
Elisabetta Malangone-Monaco ${ }^{1}$, Lenat Joffee ${ }^{2}$, Jin Zhezhen ${ }^{1}$, Dawn Hershman ${ }^{2}$, and \\ Prakash Satwani ${ }^{3}$ \\ ${ }^{1}$ Columbia University Mailman School of Public Health \\ ${ }^{2}$ Columbia University Irving Medical Center \\ ${ }^{3}$ Columbia University
}

March 22, 2021

\begin{abstract}
Background: Pediatric acute lymphoblastic leukemia (ALL) treatment regimens are lengthy, and there is limited data on the systemic and individual economic burden associated with treatment of ALL. Objective: This study aims to examine healthcare resource utilization (HCRU) and costs accrued during the first year of therapy among pediatric ALL patients, and to compare costs among those who are Commercially and Medicaid insured. Methods: Administrative claims data from 2011-16 were analyzed utilizing IBM MarketScan. Newly-diagnosed ALL patients with at least 12 months of enrollment were studied. Demographics and HCRU and costs were stratified by insurance type. The mean (standard deviation (SD) HCRU and reimbursed costs were measured during the first year post-diagnosis. Multivariable generalized linear models were run for total healthcare costs. Results: 730 (528 Commercial) patients with median age of 6 years were studied. During the 12 months following diagnosis, the mean(SD) inpatient admissions and ER visits for Commercial and Medicaid patients was 6.2(3.7) vs. $6.0(4.6), \mathrm{p}=0.6310$ and $2.8(6.4)$ vs. $2.1(2.6), \mathrm{p}=0.0380$, respectively. Commercial patients experienced more outpatient visits $(77.2(28.1)$ versus 57.4(33.3), $\mathrm{p}<0.0001)$ and less pharmacy claims $(54.1(22.9)$ and $61.0(41.8), \mathrm{p}<0.0001)$ versus Medicaid patients. Total healthcare costs were $\$ 535,135.89(\$ 547,506.23)$ versus $\$ 198,694.94(\$ 181,856.27)$, $<<0.0001$ for Commercial and Medicaid patients, respectively. When adjusted for age and gender, total healthcare costs in the year post-diagnosis for Commercial patients were 1.60 times the costs in patients with Medicaid. Conclusion: Pediatric ALL patients have high HCRU and incur significant economic burden. The total cost of care for Commercially insured patients is more than double that of Medicaid insured patients.
\end{abstract}

Date: March 13, 2021

Dr. Peter E. Newburger, M.D. Editor-in-Chief, Pediatric Blood \& Cancer

Dear Dr. Newburger,

We respectfully submit for your consideration our research article entitled "The Economic Burden of Illness in Pediatric Acute Lymphoblastic Leukemia (ALL) Patients from a Commercial and Medicaid Insurance Perspective." This study is the first to our knowledge to analyze healthcare resource utilization and costs in patients with pediatric ALL by Commercial and Medicaid insurance.

Through our analysis of 730 patients:

We observed no significant difference in the number of inpatient admissions and a borderline difference in emergency room visits for Commercial and Medicaid patients, but Commercial patients experienced 
significantly more outpatient visits and significantly less pharmacy claims compared to Medicaid patients.

Total healthcare costs were more than double for Commercial patients compared to Medicaid patients, reflecting a significant difference in total reimbursed amount for patients with Commercial and Medicaid.

The results presented in this manuscript have not been submitted elsewhere nor previously published except in abstract form (accepted, but not presented due to COVID-19 at American Society of Pediatric Hematology/Oncology (ASPHO) Annual Meeting, May 2020). All listed authors (Elisabetta Malangone-Monaco DrPH, Lenat Joffe MD, Zhezhen Jin PhD, Dawn Hershman MD and Prakash Satwani MD) have contributed to the manuscript in significant ways, all have reviewed the final version, and all agree upon the manuscript content. None of the authors have any affiliations that they consider to be relevant with any organization that, to their knowledge, has a direct interest, particularly a financial interest, in the subject matter discussed.

We suggest the following three potential reviewers: Nandita Khera (khera.nandita@mayo.edu),

Hemalatha, Rangarajan (Hemalatha.Rangarajan@nationwidechildrens.org) and Alex Seif (seifa@email.chop.edu).

We hope that you find this manuscript suitable for review and we thank you for the opportunity to have our work evaluated for publication in Pediatric Blood \& Cancer.

Sincerely,

Elisabetta Malangone-Monaco on behalf of the authors

\section{Hosted file}

MarketScan ALL PBC TITLE PAGE 3.10.21.pdf available at https://authorea.com/users/403358/ articles/514843-the-economic-burden-of-illness-in-pediatric-acute-lymphoblasticleukemia-all-patients-from-a-commercial-and-medicaid-insurance-perspective

\section{Hosted file}

MarketScan ALL Manuscript.pdf available at https://authorea.com/users/403358/articles/514843the-economic-burden-of-illness-in-pediatric-acute-lymphoblastic-leukemia-all-patientsfrom-a-commercial-and-medicaid-insurance-perspective

\section{Hosted file}

FigureTableLegendsPBC.pdf available at https://authorea.com/users/403358/articles/514843the-economic-burden-of-illness-in-pediatric-acute-lymphoblastic-leukemia-all-patientsfrom-a-commercial-and-medicaid-insurance-perspective

\section{Hosted file}

MarketScan ALL PBC 2.1.21 FIGURE 1.pdf available at https://authorea.com/users/403358/ articles/514843-the-economic-burden-of-illness-in-pediatric-acute-lymphoblasticleukemia-all-patients-from-a-commercial-and-medicaid-insurance-perspective

\section{Hosted file}

MarketScan ALL PBC 2.1.21 TABLE 1.pdf available at https://authorea.com/users/403358/ articles/514843-the-economic-burden-of-illness-in-pediatric-acute-lymphoblasticleukemia-all-patients-from-a-commercial-and-medicaid-insurance-perspective

\section{Hosted file}

MarketScan ALL PBC 2.1.21 TABLE 2.pdf available at https://authorea.com/users/403358/ articles/514843-the-economic-burden-of-illness-in-pediatric-acute-lymphoblasticleukemia-all-patients-from-a-commercial-and-medicaid-insurance-perspective 


\section{Hosted file}

MarketScan ALL PBC 1.20.21 TABLE 3.pdf available at https://authorea.com/users/403358/ articles/514843-the-economic-burden-of-illness-in-pediatric-acute-lymphoblasticleukemia-all-patients-from-a-commercial-and-medicaid-insurance-perspective

\section{Hosted file}

MarketScan ALL PBC 1.20.21 TABLE 4.pdf available at https://authorea.com/users/403358/ articles/514843-the-economic-burden-of-illness-in-pediatric-acute-lymphoblasticleukemia-all-patients-from-a-commercial-and-medicaid-insurance-perspective

\section{Hosted file}

MarketScan ALL PBC 1.20.21 TABLE 5.pdf available at https://authorea.com/users/403358/ articles/514843-the-economic-burden-of-illness-in-pediatric-acute-lymphoblasticleukemia-all-patients-from-a-commercial-and-medicaid-insurance-perspective 